\title{
INFORMATION LITERACY: UMA ANÁLISE NAS BIBLIOTECAS ESCOLARES DA REDE PRIVADA EM NATAL / RN
}

\author{
Clediane de Araújo Guedes \\ Gabriela Belmont de Farias \\ "Quem acende uma luz é o primeiro a beneficiar-se da claridade". \\ Chesterton
}

\section{Resumo}

Apresenta a information literacy, como competência em informação, relata, de forma geral, seu surgimento, desenvolvimento e importância de sua prática na biblioteca escolar. Aborda-se os principais focos da competência em informação: tecnologia da informação, processos cognitivos, e aprendizado ao longo da vida. Relata-se a análise dos dados dos questionários aplicados nas bibliotecas escolares da rede de escolas privadas da cidade de Natal RN com fins de identificar e analisar a competência em informação neste ambiente. Apresenta-se a necessidade de integração entre escola-biblioteca, e a inserção do bibliotecário na comunidade educacional para criação de programas educacionais voltados para a competência em informação.

\section{Palavras-chave}

Competência em informação; Habilidades informativas; Biblioteca escolar; Educação e aprendizagem

\section{INFORMATION LITERACY: AN ANALYSIS OF THE SCHOOL LIBRARY OF THE PRIVATE SCHOOLS NETWORK IN NATAL RN}

\begin{abstract}
It presents information literacy as information competence, as well as reporting, in a general way its appearance, development and the importance of its practice in the school library. Focuses on the main information competences: information technology, cognitive processes and life long learning. It reports on the analysis of data obtained from the questionnaire applied in school libraries of the private schools network in the city of Natal $\mathrm{RN}$, as a means to identify and analyze information competence in this environment. The need for school-library integration is presented, as is the need for the insertion of the librarian in the educational community for the creation of educational programs directed towards information competence.
\end{abstract}

\section{Key Words}

Information competence; Informative skills; School library; Education and learning 


\title{
1 INTRODUÇÃO
}

É possível determinar os momentos históricos da sociedade e seus maiores bens de consumo da época. Na sociedade medieval (séc. XV), o importante era a terra, sendo esta o produto de subsistência. Em seguida, veio a sociedade industrial (séc. XIX), tendo como insumo o capital, que centralizou a produção mecanizada de bens materiais. Hoje, na era do conhecimento, ou seja, na sociedade da informação (sécs. XX - XXI), o insumo é a informação, que tem como produto bens ativos, intangíveis, e a constante aprendizagem. Conforme Miranda (2004, p. 113), vivemos em “uma sociedade onde a informação e o conhecimento tornam-se fatores integrantes da produção”.

Assim, a sociedade da informação é caracterizada por marcantes transformações, que se têm refletido nos mais variados setores, alterando sobremaneira as formas e métodos de trabalho dos profissionais da informação, principalmente dos bibliotecários (devido a um cenário de evolução tecnológica que teve um profundo impacto nas bibliotecas e serviços de informação). Decorrente disso, surge um novo significado para essas organizações, em que, todos os dias, surgem novas formas de comunicação, novos meios eletrônicos, novas formas de compra e venda, novos meios de negociação: influência total do saber, do poder, do uso da tecnologia e do uso da informação, passa a adquirir valor econômico e a gerar transformações, como constata Takahashi, (2000, p.5):

\begin{abstract}
A sociedade da informação não é um modismo. Representa uma profunda mudança na organização da sociedade e da economia, havendo quem a considere um novo paradigma técnico-econômico. É um fenômeno global com elevado potencial transformador das atividades sociais e econômicas, uma vez que a estrutura e a dinâmica dessas atividades inevitavelmente serão, em alguma medida, afetadas pela infra-estrutura de informações disponíveis.
\end{abstract}

Estes são aspectos que explicam como se vive na conhecida e presente sociedade da informação onde esta é a base do desenvolvimento, da negociação e da gestão. Espera-se que essas tecnologias possam potencializar o intelectual das pessoas, transformando dados em informação, e esta em conhecimento, utilizando, assim, de amplas redes, sejam pessoais ou eletrônicas. Ainda sobre a sociedade da informação, Takahashi (2000, p.3) reporta-se a 
“uma nova era em que a informação flui a velocidade e em quantidade há apenas poucos anos inimagináveis, assumindo valores sociais e econômicos fundamentais”.

É nesse contexto acelerado da manipulação da informação que reconhecemos a necessidade de usar ferramentas adequadas e técnicas de acesso para melhorar a busca e uso da informação certa e na hora certa.

De acordo com Hatschbach (2002, p. 10):

Os indivíduos que pretendem ser agentes de transformação e conquistar seu espaço na sociedade da Informação necessitam adquirir habilidades específicas para o trato com a informação no que se refere a sua localização, acesso, uso, comunicação e, principalmente, para a geração de novos conhecimentos.

Como vimos, a educação é base essencial na sociedade da informação. A educação é um estudo contínuo; precisamos embutir, na comunidade educativa, a cultura de habilidades de uso da informação e as competências do manuseio dos diversos meios de trabalho. Conforme as diretrizes contidas no Livro Verde da Sociedade da Informação no Brasil:

Educar em uma sociedade da informação significa muito mais que treinar as pessoas para o uso das tecnologias de informação e conhecimento: trata-se de investir na criação de competências suficientemente amplas que lhes permitam ter decisões fundamentais no conhecimento, operar com fluência os novos meios e ferramentas em seu trabalho, bem como aplicá-los criativamente nas novas mídias, seja em usos simples e rotineiros, seja em aplicações mais sofisticadas. Trata-se também de formar os indivíduos para 'aprender a aprender', de modo a serem capazes de lidar positivamente com a contínua e acelerada transformação da base tecnológica. (TAKAHASHI, 2000, p.3).

É preciso aprender a aprender; aprender a ler criticamente; aprender a manusear informações em diversos suportes, em virtude do excesso de informações e da oferta constante das tecnologias presentes no nosso dia-a-dia. A educação hoje está voltada para os processos de construção, gestão e disseminação do conhecimento, com ênfase no aprender e no aprendizado ao longo da vida (BELLUZO, 2005b). As bibliotecas escolares, como agentes envolvidos nos processos de geração, gestão e disseminação da informação 
necessitam desempenhar habilidades de uso da informação, ou seja, ensinar os alunos a: definir suas necessidades, acessar, selecionar, avaliar, organizar, usar e gerar seu próprio conhecimento. Os bibliotecários das bibliotecas escolares precisam desenvolver em parceria com as escolas e os professores, projetos que as transformem em verdadeiros espaços de expressão, construção de conhecimento e conseqüente aprendizado.

Neste sentido, surge uma área de estudos e de programas educacionais que trata especificamente das questões relacionadas ao desenvolvimento de competências e habilidades necessárias à busca, ao uso e à compreensão da informação, voltada para a formação escolar, profissional e social, destacando a information literacy, ou competência em informação.

Pretende-se, neste trabalho, abordar teoricamente o termo information literacy como competência em informação, identificando e analisando sua prática no ambiente da biblioteca escolar da rede privada da cidade de Natal / RN. O interesse desse tema surgiu a partir de leituras prévias sobre o assunto, instigando a curiosidade de melhor compreender a aplicabilidade da information literacy no ambiente da biblioteca escolar.

\section{INFORMATION LITERACY OU COMPETÊNCIA EM INFORMAÇÃO}

O termo information literac, foi utilizado pela primeira vez, segundo Dudziak (2003, p.23), no relatório do Bibliotecário americano Paul Zurkowski, intitulado The information service environmental relation ships and priorities, em 1974, no qual Zurkowski apud Hatschbach (2002, p.16) afirma que:

\footnotetext{
Pessoas treinadas para a utilização de fontes de informação em seu trabalho podem ser chamadas de 'competentes em informação' (information literacy). Elas aprendem técnicas e ferramentas informacionais como fontes primárias para encontrarem informação, visando à solução de seus problemas.
}

Considera-se assim que não se trata apenas de fazer a busca pela informação e sim, saber fazer uso crítico da mesma para tomar decisões e resolver problemas. 
Foi então a partir de 1974, que se procederam a diversos estudos para implantar, acompanhar e avaliar a information literacy. Em 1988, a American Association of School Librarians (AASL), em conjunto com Association for Educational Communications and Technology (AECT), EUA, divulgou as diretrizes para a implementação de programas educacionais em bibliotecas do ensino médio a partir de um documento denominado Information Power: Guidelines for School Libraries Media Programs, que apresentava a interdisciplinaridade entre os bibliotecários, professores e diretores de escolas, no planejamento de estratégias de aprendizagem de acordo com as necessidades dos estudantes. As diretrizes incluem: acesso físico e intelectual aos materiais em todos os formatos; orientação para desenvolver habilidades de pensar, ouvir, ver e estimular o interesse pela leitura. Pelo uso da informação e das idéias, torna-los efetivos usuários de informação, ensinando-os a aprender a aprender. Enfoca-se assim, o papel educacional das bibliotecas e a importância dos programas educacionais em information literacy. Concordando com a idéia de perceber a biblioteca como ambiente educacional e espaço de aprendizagem, Breivik e Gee apud Dudziak, (2001, p. 31) afirma que as bibliotecas:

\footnotetext{
[...] são ambientes naturais para a resolução de problemas dentro de um universo ilimitado de informações. As bibliotecas proporcionam a estrutura necessária para a síntese de conhecimentos especializados num contexto social. E finalmente, bibliotecas e bibliotecários podem ajudar os estudantes a se tornarem competentes ('literates') em informação.
}

A construção do conhecimento, a partir da busca e do uso da informação no ambiente educacional, requer instrução e suporte durante o processo de pesquisa.

De acordo com Dudziak (2001) e Hatschbach (2002), a evolução da information literac, procedeu de forma que, na década de 70, caracterizou-se pela ênfase de que a informação é essencial à sociedade. Na década de 80, a information literacy reaparece com um novo conjunto de habilidades ligadas à eficiência e à eficácia no acesso e na utilização da informação como contribuição ao processo de aprendizagem, ao pensamento crítico, à educação baseada em recursos, relacionados ao desenvolvimento tecnológico. Já 
na década de 90, a information literacy teve sua ampliação através da definição da American Library Association (ALA) em 1989:

\begin{abstract}
Para ser competente em informação, uma pessoa deve ser capaz de reconhecer quando uma informação é necessária e deve ter a habilidade de localizar, avaliar, e usar efetivamente a informação [...] Resumindo, as pessoas competentes em informação são aquelas que aprenderam a aprender. Elas sabem como aprender, pois sabem como a informação é organizada, como encontrá-la e como usar a informação de forma que outras pessoas aprendam a partir dela. (ALA Presidential Committee on Information Literacy, 1989, p.1)
\end{abstract}

De acordo com a ALA (1989), os requisitos básicos para o indivíduo ser competente em informação são: saber buscar, avaliar, filtrar e usar a informação quando necessária. Estes requisitos justificam a integração da information literacy no currículo escolar, diminuindo a lacuna existente entre sala de aula e biblioteca, ou seja, estimulam os estudantes ao uso dos recursos informacionais de forma contextualizada a fim de incutir neles o hábito de buscar e utilizar a informação e a biblioteca para a aprendizagem e a resolução de problemas. A partir dessa definição da ALA, os bibliotecários e educadores passaram a desenvolver o interesse pela implantação de programas educacionais voltados para a information literacy, com o objetivo de tornar os usuários aprendizes independentes, enfatizando a integração do currículo à cooperação e à comunidade. Nesse momento, entra em destaque o conceito de aprendizagem ao longo da vida. A esse respeito, Kuhlthau (2002) apud Hatschbach (2002, p.18), comenta: “a busca de informação é um processo de construção que envolve a experiência de uma vida, os sentimentos, bem como os pensamentos e as atitudes de uma pessoa”.

No Brasil, vários pesquisadores estão contribuindo para o avanço dos estudos sobre Information Literacy ou Competência em Informação. Dentre eles, podemos citar os autores da área da ciência da informação: Campello (2003) e Hatschbach (2002). Para melhor clareza do assunto, podemos citar os conceitos das autoras referidas: Dudziak (2003, p.28) apresenta sua definição sobre information literacy com ênfase no aprendizado ao longo da vida, assim: 
information literacy é o processo contínuo de internacionalização de fundamentos conceituais, atitudinais e de habilidades necessárias à compreensão e interação permanente com o universo informacional e sua dinâmica, de modo a proporcionar um aprendizado ao longo da vida

Campello (2003, p.36) aborda a information literacy como:

competência informacional, e defende que no cenário da biblioteca escolar, deve ser considerada como panorama dos estudos sobre letramento, que é o conceito utilizado no âmbito do ensino básico para designar o estado ou condição que assume aquele que aprende a ler e a escrever, entendendo-se então que quem aprende a ler e a escrever e passa a usar a leitura e a escrita, torna-se uma pessoa diferente.

Já Hatschbach (2002, p. 95) resume que:

a competência em informação é uma área de estudos e de práticas que trata das habilidades acerca do uso da informação em relação à sua busca, localização, avaliação, e divulgação, integrando a utilização de novas tecnologias e a capacidade de resolução e problemas de informação.

E finalmente Belluzzo (2005b, p.38) afirma que:

a competência em informação constitui-se em processo contínuo de interação e internalização de fundamentos conceituais, atitudinais e de habilidades específicas como referenciais à compreensão da informação e de sua abrangência, em busca da fluência e das capacidades necessárias à geração do conhecimento novo e sua aplicabilidade ao cotidiano das pessoas e das comunidades ao longo da vida.

Diante da diversidade de expressões que representam a information literacy no idioma português, tais como: alfabetização informacional, letramento, competência informacional, e competência em informação, verifica-se a predominância da tradução do termo information literacy no campo das ciências da informação como competência em informação, pois, mesmo que seja em abordagens distintas, abrange os principais aspectos relacionados ao seu conceito, o que representa a habilidade e a capacidade de usa-la.

A definição de “competência” na área de educação visa como referencial é a do sociólogo Philippe Perrenoud: “competência em educação é a faculdade de mobilizar um conjunto de recursos cognitivos - como saberes, habilidades e informações - para 
solucionar com pertinência e eficácia uma série de situações.” (GENTILE, 2000, p.13). Assim, comenta Belluzzo (2005a) que, para Perrenoud, as competências utilizam, integram, mobilizam conhecimentos para enfrentar um conjunto de situações complexas. No dicionário Aurélio, a definição encontrada é: “qualidade de quem é capaz de apreciar e resolver certo assunto, fazer determinada coisa; capacidade, habilidade, aptidão, idoneidade” (FERREIRA, 2004, p. 508). Constata-se nas definições acima a adequação da aplicação do termo no contexto de resolução de problemas, componente importante da information literacy.

A partir da análise da evolução de competência em informação verificam-se diferentes concepções. Em destaque, apresentamos as três mais abordadas no cenário da sociedade da informação, de acordo com as autoras Belluzzo (2005a, p.37; 2005b, p.37) e Dudziak (2003, p. 30):

1) Competência em informação na concepção da informação digital - ênfase na tecnologia da informação e da comunicação;

2) Competência em informação na concepção da informação propriamente dita ênfase nos processos cognitivos;

3) Competência em informação na concepção da informação social - ênfase na inclusão social, no aprendizado ao longo da vida como exercício de cidadania.

Para o desenvolvimento dessas competências, é preciso que todas as pessoas tenham responsabilidade e sejam educadas para enfrentar a sociedade, adquirindo conhecimentos de mecanismos de buscas e uso de informações em ambientes eletrônicos para a construção do conhecimento, envolvendo uso, interpretação e buscas de significados. Além de uma série de habilidades e conhecimentos, devem ter a noção de valores ligados à dimensão social e situacional, tornando o indivíduo como sujeito aprendente, indivíduo enquanto ator 


\section{RELATO DE EXPERIÊNCIA}

social. (DUDZIAK, 2003). Ao longo dessas abordagens, percebe-se a importância do papel da biblioteca escolar no desenvolvimento das competências em informação.

\section{BIBLIOTECA ESCOLAR - ESPAÇO DE COMPETÊNCIA EM INFORMAÇAO}

A partir da nova Lei de Diretrizes e Bases para a Educação Nacional (LDB), promulgada em 1996, foram criados os Parâmetros Curriculares Nacionais - PCN, lançado em 1999, que redistribuiram o trabalho da comunidade educacional do país, passando a ser interdisciplinares. Os mesmos propõem o desenvolvimento de competências e habilidades na associação ensino-pesquisa, contribuindo de forma efetiva para que os educandos construam conhecimentos e desenvolvam autonomia intelectual. (SECRETARIA DE EDUCAÇÃO MÉDIA E TECNOLÓGICA, 2002). Isso nos leva a considerar que essa nova conduta educacional consolida a posição do educador como um facilitador do processo de ensino aprendizagem. Milanesi apud Belluzzo (2005a, p.33), afirma que:

uma prática de ensino, para incluir a leitura e a discussão, exige transformações na escola, mudando a cena, alterando a sala de aula, mudando o papel do professor de mero transferidor de conteúdo, incrementado a biblioteca incentivando todas as formas de acesso à informação registrada e a produção de novas informações.

Neste cenário de mudanças da educação é que contextualizamos a competência em informação no ambiente da biblioteca escolar e entendemos a necessidade de ampliar a função pedagógica da biblioteca, como comenta Campello (2003); faz-se necessário construir um novo paradigma educacional para a biblioteca. Esta deve deixar de ser apenas um repositório de informações e prestadora de serviços, para se transformar em organização aprendente e espaço de expressão, adotando práticas de inovação organizacional (DUDZIAK, 2003). Segundo definição da Organização das Nações Unidas para a Educação, a Ciência e a Cultura - UNESCO, a biblioteca escolar cria oportunidades para desenvolver ensino e aprendizagem conforme afirma:

A biblioteca escolar (BE) propicia informação e idéias fundamentais para seu funcionamento bem sucedido na atual sociedade, baseada na informação e no 
conhecimento. A BE habilita os estudantes para a aprendizagem ao longo da vida e desenvolve a imaginação, preparando-os para viver como cidadãos responsáveis. (MANIFESTO IFLA/UNESCO PARA BIBLIOTECA ESCOLAR, 1999)

Como parte do sistema educacional, a biblioteca escolar tem o objetivo de mediar os processos de busca e uso da informação, levando o aluno a formar seu próprio significado a partir do acesso à informação. Ela também auxilia os educadores na complexa tarefa de desenvolver nos alunos, de maneira sistemática, habilidades para lidar com a informação. Conforme Kuhlthau (2002, p. 10):

Reunidos no espaço da biblioteca escolar, os recursos informacionais irão se constituir num rico manancial para propiciar o desenvolvimento de conhecimentos, habilidades e atitudes necessárias para viver e conviver na sociedade da informação.

É o contato com esse manancial de informações, que faz com que se realize a pesquisa escolar, uma questão de interesse entre bibliotecários e professores. Esta constitui uma das principais atividades realizadas no processo de ensino e aprendizagem, influenciando, desde as séries iniciais, na formação e desenvolvimento social do aluno. Alguns princípios fundamentais são aqui apresentados: auxiliar os alunos a estudar com independência, planejar, conviver, e interagir em grupo, conhecer e aceitar as opiniões dos outros; usar adequadamente os recursos informacionais, tais como bibliotecas e outras fontes de pesquisas; desenvolver o pensamento crítico e o gosto pela leitura; adquirir autonomia no processo do conhecimento; aprender a trabalhar de forma colaborativa (BELLUZZO, 2005a).

Essa mesma autora conceitua pesquisa como "um processo racional e sistemático, planejado e desenvolvido com apoio do método reflexivo e que requer um tratamento científico, tendo como objetivo buscar respostas e soluções a problemas sugeridos” (BELLUZZO, 2005a, p.34). Muitas vezes, essa não é a realidade da escola, onde geralmente o aluno pesquisa de forma rápida para cumprir tarefa e ser avaliado pelo professor, ocasionando que ele não realize nenhum procedimento metodológico. No mundo 
atual, diante das ferramentas tecnológicas, a pesquisa é um desafio para a escola, visto que antigamente, a pesquisa era realizada em documentos impressos, mediante o uso de materiais bibliográficos e / ou através do método da entrevista. Hoje, é preciso elaborar estratégias para a utilização dos recursos tecnológicos, que facilitam as pesquisas mas também as tornam complexas, na medida do montante de informações, surgindo a necessidade do desenvolvimento de novas habilidades para uso das novas tecnologias. Torna-se importante que o professor e o bibliotecário oportunizem o acesso às ferramentas de pesquisa, estimulando os alunos a ampliarem suas informações, desenvolver a curiosidade e o espírito crítico. As estratégias para o melhor uso das tecnologias devem propiciar a interação entre o bibliotecário, os professores e os alunos e estes entre si, criando um ambiente de estímulo e apoio às atividades de ensino e de aprendizagem. Faqueti; Vanin; Blattmann (2005, p. 2) consideram:

a pesquisa no ambiente escolar como um conjunto de ações que envolvem desde o encantamento por um tema/problema até sua apresentação final, o rol de atuação da biblioteca e do bibliotecário(a) abrange inúmeras funções motivadoras na leitura e escrita.

É interessante lembrar que, para a biblioteca escolar ser ativa e engajada no processo de ensino-aprendizagem, ela precisa do profissional bibliotecário, capaz de projetar um futuro superior para os ambientes informacionais da escola, tornando a biblioteca um importante agente de mudanças. Campello (2003, p.43) aborda que “o bibliotecário é a figura central no discurso da competência informacional”. Já Dudziak (2003, p.33) afirma que "a cooperação entre administradores, bibliotecários, docentes e técnicos é uma das premissas para que se desenvolvam programas educacionais voltados para information literacy”. Vários autores ressaltam a importância da parceira entre o bibliotecário e os professores junto a toda a comunidade educativa da escola.

A biblioteca e o bibliotecário ganham destaque nas três concepções da competência em informação citadas por Dudziak (2003 p. 30), são elas: 


\section{RELATO DE EXPERIÊNCIA}

1) A biblioteca aparece como suporte ao ensino-aprendizagem e proporciona o acesso físico à informação organizada, com o aprendizado de mecanismos de busca e uso de informações em ambientes eletrônicos. O bibliotecário assume o papel de intermediário da informação, auxiliando apenas na organização e recuperação de informações. O foco está na recuperação da informação como o objetivo principal.

2) A biblioteca é concebida como espaço de aprendizado, envolvendo uso, interpretação, buscas de significados, construção de conhecimento significativo. O bibliotecário aparece como gestor do conhecimento e ou como mediador nos processos de buscas (auxiliar, guiar, intervir, orientar). Ele é visto como facilitador no processo educacional ou de aprendizagem e deve ser parte da equipe educacional. O foco é direcionado ao indivíduo enquanto possuidor de habilidades, conhecimentos e valores pessoais.

3) A biblioteca é representada como cenário de expressão do sujeito e espaço de aprendizagem (valores pessoais, ética, autonomia, responsabilidade, criatividade, pensamento crítico e o aprender a aprender), e o bibliotecário transforma-se em agente educacional e torna-se aprendiz, engajado em movimentos sociais, em cooperação com os colegas. O foco será a sociedade de aprendizado.

Analisando a biblioteca escolar como espaço de competência em informação, constatamos a atuação do bibliotecário como agente educacional, que deve direcionar seu trabalho para a mediação de aprendizado. De acordo com Belluzzo (2005a), entende-se que a competência em informação deve ser compreendida como uma das áreas em que o processo de ensino e aprendizagem esteja centrado. Dudziak (2003) compartilha a mesma idéia ao afirmar que, neste sentido, a biblioteca torna-se uma instituição multicultural, pluralista e aprendente. Desse modo, faz parte do trabalho dos bibliotecários criar, desenvolver e implantar programas sobre competências, visando à formação dos alunos, de forma que não baste apenas ensinar leitura e escrita, mas dar condições mínimas de idéias de acesso e uso das informações, transformando a forma de pensar e de se relacionar com a 
realidade. Neste propósito, são apresentadas por Dudziak (2005) as melhores práticas recomendadas por autores e entidades internacionais que desenvolvem programas e projetos voltados à educação para competência em informação. São elas:

1. O bibliotecário deve ser um campeão de causa;

2. O centro do processo é o aluno;

3. O bibliotecário deve ser um agente educacional;

4. É preciso haver cooperação entre docentes e bibliotecários;

5. A cultura do livre acesso à informação deve ser enfatizada;

6. A inserção do projeto pedagógico;

7. Definição clara de objetivos e metas;

8. Planejamento é essencial;

9. A transdisciplinaridade e o currículo integrado como marcos para a competência em informação;

10. Incorporar diferentes espaços de aprendizagem;

11. As melhores práticas decorrem do decorrer do processo;

12. Avaliação constante e controle do processo.

Desenvolver projetos pedagógicos na área da competência em informação é missão do bibliotecário com o objetivo de educar os alunos na hora de acessar e usar a informação, tornando-o, assim, um agente educacional em compartilhamento com os professores. Ele faz surgir a democratização da informação, em conjunto com a equipe pedagógica e a política educacional da instituição; define a construção do conhecimento com planejamento, integrando os conteúdos às práticas adequadas que privilegiam a competência em informação. É nesta visão que encontramos o futuro das bibliotecas escolares, apoiando os processos de desenvolvimento de habilidades informativas para a aprendizagem. 
Diante do contexto apresentado, a proposta desta pesquisa é identificar e analisar a competência em informação nas bibliotecas escolares da rede privada da cidade de Natal / RN.

\section{METODOLOGIA}

Para a viabilidade do objetivo traçado, foram utilizadas estratégias distintas para delimitar o campo de coleta dos dados, objetivando avaliar as bibliotecas das escolas particulares de Natal / RN, bem como a presença do profissional bibliotecário neste espaço, e se é desenvolvida nas bibliotecas alguma prática de competência em informação. As estratégias traçadas foram as seguintes:

Campo de pesquisa - segundo o anuário estatístico do Instituto de Desenvolvimento Econômico e Meio Ambiente do Rio Grande do Norte - IDEMA (RIO GRANDE DO NORTE..., 2003), há um universo de 231 estabelecimentos de ensino particular na cidade de Natal (RN), no qual foi feito um recorte através dos seguintes critérios: a escola deve oferecer ensino fundamental e médio, além de possuir em sua infra-estrutura uma biblioteca sob a coordenação do profissional bibliotecário. Isto resultou em um universo pesquisado de 10 (dez) escolas, por estarem dentro dos critérios necessários para desenvolver a pesquisa.

Ressalva que a formação do profissional bibliotecário no estado do Rio Grande do Norte - RN é recente. A universidade federal do RN é a única a oferecer o curso de graduação em biblioteconomia, inserindo no mercado de trabalho sua primeira turma em 2001. O que denota enorme necessidade de incentivo por parte da classe bibliotecária em socializar a profissão no âmbito da biblioteca escolar na cidade de Natal (RN). Talvez por este motivo, apenas as dez escolas selecionadas possuam em seu quadro funcional bibliotecários. 
Referencial teórico - estudo exploratório do tema information litrracy, desde seu surgimento e desenvolvimento, até os dias atuais, para melhor conhecimento e aprofundamento do assunto abordado, através do levantamento bibliográfico.

Método - foi realizada entrevista presencial, no ambiente de trabalho, utilizando como instrumento de pesquisa um roteiro de entrevista semi-estruturado, o qual é composto de três principais áreas: a tecnologia da informação, os processos cognitivos e o aprendizado ao longo da vida. A formulação do roteiro de entrevista teve como objetivo identificar se a biblioteca escolar juntamente com o bibliotecário, está proporcionando um ambiente que fomente o uso e a compreensão da informação, com o interesse de obter dados relacionados ao desenvolvimento da competência em informação no ambiente das bibliotecas escolares. O termo information literacy, é explicado na entrevista com intenção de inserir o bibliotecário entrevistado no contexto da pesquisa. Para realização das entrevistas, foi necessário agendar encontros com os bibliotecários responsáveis pela biblioteca escolar através de ligações telefônicas. As entrevistas ocorreram no período de junho a agosto de 2005.

\section{ANÁLISE DOS RESULTADOS}

Foram entrevistadas 08 bibliotecárias das dez instituições selecionadas, já que as outras duas instituições sempre mantêm bibliotecários em seu quadro de funcionários, mas, no momento da pesquisa, estavam em processo seletivo. As entrevistadas se mostraram acessíveis e interessadas pelo tema. Pode-se perceber que a profissão é predominantemente feminina, já que $100 \%$ dos profissionais entrevistados foram do sexo feminino.

Constatou-se que os sujeitos participantes da pesquisa, em sua maioria, estão iniciando um trabalho em biblioteca escolar, ou seja, 85\% têm menos de quatro anos de trabalho no ambiente escolar, o que resulta um tempo de trabalho reduzido para organização, automatização e implantação de trabalhos pedagógicos que influencie na criação de programas de competência em informação. 
Observa-se também que $70 \%$ das bibliotecárias entrevistadas são formadas há menos de cinco anos. Presume-se que a maioria teve oportunidade de cursar disciplinas da grade curricular implantada pelo Ministério da Educação. Nesta, a influência das tecnologias de informação no currículo de biblioteconomia culminou com o trabalho dos profissionais bibliotecários, no cerne da questão do aprendizado, pelo uso das tecnologias da informação acessando-as de forma independente ou mediada, contribuindo assim, para a construção do conhecimento.

Depois de analisada a caracterização do sujeito, o questionário teve como análise de interesse três principais áreas: a tecnologia da informação, os processos cognitivos e o aprendizado ao longo da vida. Veremos agora cada um deles:

1) A Tecnologia da informação: este bloco de perguntas buscou conhecer a profundidade com que a biblioteca escolar faz uso das novas tecnologias para incentivar o aprendizado.

No que diz respeito às ferramentas das novas tecnologias de informação e comunicação utilizadas no ambiente da biblioteca escolar, foi respondi o seguinte: - 90\% das entrevistadas utilizam fontes eletrônicas para subsidiar as pesquisas através da Internet, como também através do uso do catálogo on-line.

Quanto ao quesito treinamento das pesquisas/buscas em ambientes eletrônicos, 60\% das entrevistadas responderam coordenar algum trabalho específico com o intuito de aperfeiçoar as buscas, mas não de forma coletiva e sim como auxílio individual; 40\% das entrevistadas preparam treinamentos para seus usuários de forma a atender a toda a comunidade educativa da instituição.

2) Os Processos Cognitivos: em linhas gerais, buscou-se colher a opinião do bibliotecário a respeito dos métodos para estimular o aprendizado e a compreensão do uso da informação pelo aluno. 
Foi questionado, em pergunta aberta, o que a biblioteca oferece para estimular o aprendizado e a compreensão do uso da informação pelo aluno. Verifica-se que $50 \%$ das entrevistadas desenvolvem atividades com toda a comunidade educativa (alunos, professores e funcionários), abordando a conservação, a preservação, o acesso e o uso da informação, através de visitas programadas, painéis explicativos, orientação à pesquisa, aulas agendadas com os professores, projetos de educação/orientação no uso das fontes de informação, integração da biblioteca com a semana da feira científico/cultural. Essas atividades contribuem com a compreensão sobre questões legais, éticas e sócioeconômicos, que envolvem a informação e a tecnologia (BELLUZZO, 2004b).

Mesmo aferindo que atualmente apenas 50\% desenvolvem esse tipo de atividade com o intuito de contribuir com o ensino e aprendizagem da formação dos alunos - os 50\% restantes percebem a sua importância, encontrando-se, portanto, em vias de implantação.

Com relação ao incentivo à leitura, foi verificado que 75\% das bibliotecas realizam uma variedade de atividades que estimulam o aprendizado, sendo elas: contação de histórias, produção de textos, concursos literários, exposições, sala de bate-papo com escritores, mural com dicas de leituras, rodas de leitura, premiação para leitores destaques, semana do livro e da biblioteca e gincanas literárias. Neste sentido, a biblioteca visualiza os alunos como sujeitos da cultura, capazes de criarem e de re-elaborarem informações e experiências dentro do processo educativo.

Quanto à orientação para elaboração e apresentação dos trabalhos escolares, foi constatado que apenas 37,5\% das bibliotecárias entrevistadas realizam treinamento para padronizar os trabalhos escolares dentro dos padrões da Associação Brasileira de Normas Técnicas - ABNT, como forma de abrangência de toda a comunidade educativa, no qual um sujeito da pesquisa afirma: "são dadas aulas de referência, citação e apresentação de trabalho pelos alunos da $5^{\mathrm{a}}$ série ao $2^{\circ}$ ano do ensino médio", envolvendo assim alunos, professores e bibliotecários. Enquanto 62,5\% das bibliotecas consideram oferecer este 


\section{RELATO DE EXPERIÊNCIA}

serviço, ainda que de forma modesta, pois o processo começa com o professor em sala de aula, ao passo que, na biblioteca fica a etapa de orientação pessoal, deixando claro que faz parte do projeto de desenvolvimento da biblioteca realizar treinamento para todos; este, porém, ainda está em fase de implantação.

3) O Aprendizado ao longo da vida: esta etapa propõe obter informações quanto ao ambiente da biblioteca, à relação do bibliotecário com os professores, equipe pedagógica, e se há integração da biblioteca com a sala de aula.

Quanto ao ambiente da biblioteca, foi avaliado se é apresentado de forma a ser rico em informações, onde o aluno aprende a aprender. Neste quesito, 75\% das bibliotecas avaliadas responderam que seu ambiente é bem sinalizado e organizado, de forma que vem propiciar um alto atendimento. A biblioteca, quando é auto-explicativa, facilita o aprendizado e se transforma em espaço de expressão.

No que diz respeito à interdisciplinaridade do bibliotecário junto aos profissionais que formam a equipe pedagógica da escola, apenas 50\% trabalham em conjunto com esta equipe; porém foi relatado que ainda existem algumas barreiras a serem transpostas, dentre as quais destaca-se como principal obstáculo a falta de conhecimento por parte dos outros profissionais da equipe pedagógica no que tange, ao real papel do bibliotecário no processo de ensino-aprendizagem do aluno. Mesmo com essas dificuldades, foi observado que $75 \%$ das bibliotecárias entrevistadas concordam que a biblioteca interage de forma ativa na vida escolar do aluno e que há de fato integração entre sala de aula e biblioteca, mesmo que seja por parte de alguns professores.

O instrumento utilizado para coleta de dados permitiu uma visualização e compreensão mais ampla das possibilidades de ação conjunta entre bibliotecas, bibliotecários e escolas; os resultados aqui apresentados atendem a cada um dos focos mencionados, constatando-se a necessidade de investir em programas de aprendizagem que contemplem, desde a utilização das tecnologias de informação para a recuperação e 
comunicação da informação, à aproximação do ensino baseado na solução de problemas e à realização de projetos investigativos, estimulando o aprendizado independente.

\section{CONSIDERAÇÕES FINAIS}

A partir da apresentação da information literacy, ou competência em informação, foi relatada a importância do desenvolvimento dessa competência na sociedade da informação, bem como no âmbito da biblioteca escolar, provocando mudanças e atitudes dos profissionais bibliotecários, mostrando-lhes a necessidade e, sobretudo, as possibilidades de ações pró-ativas voltadas para a ampliação da competência em informação dos alunos, que precisam, cada vez mais, de informação na sua vida escolar.

Dessa forma, espera-se estar contribuindo para desenvolver e incentivar o estudo sobre competência em informação, como também estreitar a relação entre bibliotecários, alunos e professores, para assim se desenvolverem ações conjuntas, visando à promoção da leitura e da pesquisa escolar enquanto formas de garantia de acesso à informação e seu uso. Assim, contribui-se, com a geração de novos conhecimentos.

Considera-se de suma necessidade a criação de programas voltados à information literacy no ambiente da biblioteca escolar. Para isto, é necessária uma atuação integrada e em cooperação com os bibliotecários, transformando as bibliotecas em serviços de informação e verdadeiros espaços de busca, expressão e construção do conhecimento. Neste contexto, faz-se preciso desenvolver no educando o processo de intelectualização, no sentido de formá-lo para saber determinar a sua necessidade de informação; identificar e manusear fontes de informação de forma eficaz; avaliar e interpretar criticamente a informação; assumir a responsabilidade do seu próprio aprendizado, tornando-os aprendiz independente e assumindo o aprendizado como criação de significados para sua vida.

A competência em informação envolve um processo de mudança a partir da quebra de paradigmas nas maneiras de se adquirir a informação pelo processo do "aprender a 
aprender”... É a própria busca por respostas, um desafio do fazer melhor, tornando-o uma eterna busca pelo saber.

\section{REFERÊNCIAS}

AMERICAN LIBRARY ASSOCIATION - ALA, 1989. Presidential committee on information literacy: final report. Disponível em: < http://www.ala.org/ala/acrl/acrlpubs/whitepapers/presidential.htm $>$ Acesso em: 3 set. 2005.

Report of the presidential committee on information literacy: an update on the american library association presential committee on information literacy: final $\begin{array}{lll}\text { report. } & \text { Disponível } & \text { em: }\end{array}$ http://www.ala.org/ala/acrl/acrlpubs/whitepapers/progressreport.htm $>$ Acesso em: 3 set. 2005.

AMERICAN ASSOCIATION OF SCHOOL LIBRARIANS - AASL. Using content from information power: building partnerships for learning, 1998. Disponível em: < http://www.ala.org/ala/aasl/aaslproftools/informationpower/InformationLiteracyStan dards_final.pdf > Acesso em: 03 set. 2005.

BELLUZZO, R. C. B. Competências na era digital: desafios tangíveis para bibliotecários e educadores. Educação Temática Digital, Campinas, v.6, n.2, p.27-42, jun.2005a.

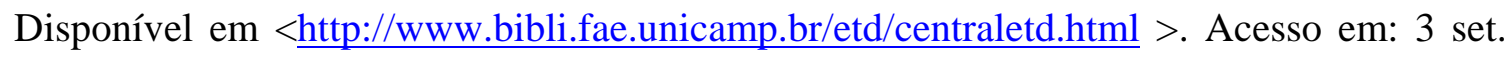
2005.

. O uso de mapas conceituais para o desenvolvimento da competência em informação: um exercício de criatividade. In: PASSOS, R.; SANTOS, G. C. (Orgs.) Competência em informação na sociedade de aprendizagem. Bauru: Kayros, 2005b. 
et al. Information literacy: um indicador de competência para a formação permanente de professores na sociedade do conhecimento. Educação Temática Digital, Campinas, v.6, n.1, p.81-99, dez.2004a. Disponível em <http://www.bibli.fae.unicamp.br/etd/centraletd.html > . Acesso em: 03 set. 2005.

; KERBAUY, M. T. M. Em busca de parâmetros de avaliação da formação contínua de professores do ensino fundamental para o desenvolvimento da information literacy. Educação Temática Digital, Campinas, v.5, n.2, p.129-139, jun.2004b.

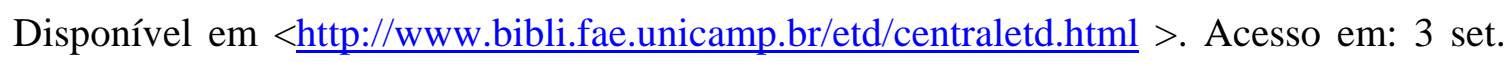
2005.

; FERES, G. G. Impacto da era digital no acesso e uso da informação e novas condutas de gestão de bibliotecas sob enfoque da competência em informação. In: CONGRESSO BRASILEIRO DE BIBLIOTECONOMIA, DOCUMENTAÇÃO E CIÊNCIA DA INFORMAÇÃO, 21., 2005, Curitiba. Anais... Curitiba: CBBD, 2005c. 1 CD-ROM

; ROSETT, M. Contribuição ao desenvolvimento da competência em informação em bibliotecas públicas paulistas: uma experiência com apoio de oficinas de trabalho. In: CONGRESSO BRASILEIRO DE BIBLIOTECONOMIA, DOCUMENTAÇÃO E CIÊNCIA DA INFORMAÇÃO, 21., 2005 Curitiba. Anais... Curitiba: CBBD, 2005d. 1 CD-ROM

CAMPELLO, B. O movimento da competência informacional: uma perspectiva para o letramento informacional. Ciência da Informação, Brasília, v.32, n.3, p. 28-37,

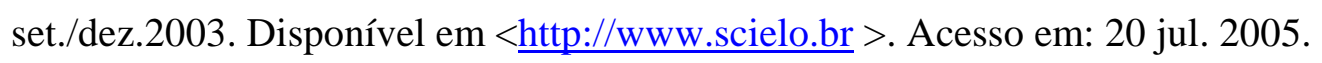

DUDZIAK, E. A. A information literacy e o papel educacional das bibliotecas. 2001.173f. Dissertação (Mestrado em Ciências da Comunicação) - Escola de Comunicação e Artes, Universidade de São Paulo, São Paulo, 2001. 
Competência em informação: melhores práticas educacionais voltadas para a information literacy. In: CONGRESSO BRASILEIRO DE BIBLIOTECONOMIA, DOCUMENTAÇÃO E CIÊNCIA DA INFORMAÇÃO, 21., 2005, Curitiba. Anais... Curitiba: CBBD, 2005. 1 CD-ROM.

Information literacy: princípios, filosofia e prática. Ciência da Informação, Brasília, v.32, n.1, p. 23-35, jan./abr.2003. Disponível em <http://www.scielo.br $>$. Acesso em: 20 jul. 2005.

FAQUETI, M. F.; VANIN, M.; BLATTMANN, U. Apresentação de trabalhos escolares: a biblioteca no processo de aprendizagem. In: CONGRESSO BRASILEIRO DE BIBLIOTECONOMIA, DOCUMENTAÇÃO E CIÊNCIA DA INFORMAÇÃO, 21., 2005, Curitiba. Anais... Curitiba: CBBD, 2005. 1 CD-ROM

FERREIRA, A. B. de H. Novo dicionário Aurélio da língua portuguesa. 3. ed. Curitiba: Positivo, 2004. p. 2120.

GENTILE, P.; BENCINI, R. Aprender (e desenvolver) competências. Revista Nova Escola, São Paulo, n.135, p.12-17, set. 2000.

HATSCHBACH, M. H. de L. Information literacy: aspectos conceituais e iniciativas em ambiente digital para o estudante de nível superior. Rio de Janeiro, 2002. 108f. Dissertação (Mestrado em Ciência da Informação) - UFRJ/ECO-MCT/IBICT, Rio de Janeiro, 2002.

KUHLTHAU, C. Como usar a biblioteca na escola: um programa de atividades para o ensino fundamental. Tradução de Bernadete Santos et al. Belo Horizonte: Autêntica, 2002. 
MANIFESTO IFLA/UNESCO PARA BIBLIOTECA ESCOLAR. Edição em língua portuguesa traduzida por Neusa Dias de Macedo. UNESCO: São Paulo, 1999. Disponível em: <http://www.ifla.org/VII/s11/pubs/portuguese-brazil.pdf > . Acesso em: 3 set. 2005.

MIRANDA, S. V. Identificando competências informacionais. Ci. Inf., Brasília, v.33, n.2, p. 112-122, maio/ago.2004. Disponível em <http://www.scielo.br >. Acesso em: 20 jul. 2005.

NATIONAL FORUM ON INFORMATION LITERACY - NFIL. Disponível em: <http://www.infolit.org>. Acesso em: 5 set. 2005.

PASSOS, R.; SANTOS, G. C. (Orgs.).Competência em informação na sociedade de aprendizagem. Bauru: Kayros, 2005.

RIO GRANDE DO NORTE. Secretaria do Planejamento e das finanças. Instituto de desenvolvimento econômico e Meio ambiente do Rio Grande do Norte. Anuário estatístico: Rio Grande do Norte - 2003. Natal: [s. n.], 2003.

SECRETARIA DE EDUCAÇÃO MÉDIA E TECNOLÓGICA. Ciências humanas e suas tecnologias. Brasília: MEC; SEMTEC, 2002. (PCN + ensino médio: orientações educacionais complementares aos parâmetros curriculares nacionais).

TAKAHASHI, T. (Org.) Sociedade da informação no Brasil: livro verde. Brasília: Ministério da Ciência e Tecnologia, 2000. 203p. 


\section{Gabriela Belmont de Farias}

Bibliotecária. Mestranda do Programa de Pós-Graduação em Ciência da Informação da UFSC. gabriela belmont@yahoo.com.br

\section{Clediane de Araújo Guedes}

Bibliotecária. Especialista em Gestão Estratégica em Sistemas de informação - UFRN Colégio Salesiano São José. Natal / RN.

cledianeguedes@hotmail.com 